Çukurova Üniversitesi Mühendislik Mimarlık Fakültesi Dergisi, 32(3), ss. 145-154, Eylül 2017

Çukurova University Journal of the Faculty of Engineering and Architecture, 32(3), pp. 145-154, September 2017

\title{
Farklı Kalsinasyon Sıcaklıklarında Elde Edilen Kostik Kalsine Manyezitlerin Yüzey Alanlarının ve Porozitelerinin Belirlenmesi
}

\author{
Mehmet TÜRKMENOĞLU*', Nil YAPICI², Mesut ANIL ${ }^{2}$, Özen KILIÇ ${ }^{2}$ \\ ${ }^{l} Y \ddot{z} z \ddot{n n c u ̈ ~ Y ı l ~ U ̈ n i v e r s i t e s i, ~ M u ̈ h e n d i s l i k ~ M i m a r l ı k ~ F a k u ̈ l t e s i, ~ M a d e n ~ M u ̈ h e n d i s l i g ̆ i ~ B o ̈ l u ̈ m u ̈, ~ V a n ~}$ \\ ${ }^{2}$ Çukurova Üniversitesi, Mühendislik Mimarlık Fakültesi, Maden Mühendisliği Bölümü, Adana
}

Geliş tarihi: 15.05.2017 Kabul tarihi: 25.09.2017

\section{$\ddot{O} z$}

Bu çalışmada, manyezit cevherinin $650{ }^{\circ} \mathrm{C}$ ile $850{ }^{\circ} \mathrm{C}$ arasındaki sıcaklıklarda kalsine edilmesi ile elde edilen kostik kalsine manyezitlerin yüzey alanları ve poroziteleri belirlenmiştir. Kimyasal analiz sonuçlarına göre, manyezit örneği \%97,02 oranında magnezyum karbonattan oluşmaktadır. Kalsinasyon sırasında karbondioksit gazının çıkışı ile birlikte, manyezit cevherinin BET yüzey alanı $2,71 \mathrm{~m}^{2} / \mathrm{g}$ 'den $70,49 \mathrm{~m}^{2} / \mathrm{g}$ 'a, Langmuir yüzey alanı ise $3,45 \mathrm{~m}^{2} / \mathrm{g}$ 'dan $91,29 \mathrm{~m}^{2} / \mathrm{g}$ 'a yükselmiștir. Yüzey alanındaki yaklaşık 25 kat artışla birlikte, toplam gözenek hacmi $5,89 \mathrm{~mm}^{3} / \mathrm{g}$ 'dan $172,70 \mathrm{~mm}^{3} / \mathrm{g}$ ' ç̧ımıştır. Kostik kalsine manyezitin kalitesini etkileyen parametreler; kalsinasyon süresi ve sıcaklı̆̆ı, ham cevherin kimyasal saflığı ve elde edilen kostik kalsine manyezitin yüzey alanıdır. Yüzey alanı arttıkça, kostik kalsine manyezitin kalitesi artmaktadır. Çalışmada, en yüksek yüzey alanına sahip kostik kalsine manyezitler $750{ }^{\circ} \mathrm{C}^{\prime}$ de elde edilmiştir.

Anahtar Kelimeler: Kostik kalsine manyezit, Kalsinasyon, Yüzey alanı, Porozite

\section{Determination of Surface Areas and Porosities of Caustic Calcined Magnesites Obtained at Different Calcination Temperatures}

\begin{abstract}
In this study, surface areas and porosities of caustic calcined magnesites were determined by calcining magnesite ore at temperatures between $650{ }^{\circ} \mathrm{C}$ and $850{ }^{\circ} \mathrm{C}$. According to the results of the chemical analysis, the magnesite sample is $97,02 \%$ magnesium carbonate. Along with the release of carbon dioxide gas during calcination, the BET surface area of the magnesite ore increased from $2,71 \mathrm{~m}^{2} / \mathrm{g}$ to $70,49 \mathrm{~m}^{2} / \mathrm{g}$, the Langmuir surface area increased from $3,45 \mathrm{~m}^{2} / \mathrm{g}$ to $91,29 \mathrm{~m}^{2} / \mathrm{g}$. The total pore volume increased from $5,89 \mathrm{~mm}^{3} / \mathrm{g}$ to $172,70 \mathrm{~mm}^{3} / \mathrm{g}$ with an increase of about 25 times in the surface area. Parameters affecting the quality of caustic calcined magnesite are; The calcination duration and temperature, the chemical purity of the crude ore, and the surface area of the obtained caustic calcined magnesite. As the surface area increases, the quality of caustic calcined magnesite increases. In the study, caustic calcined magnesites with the highest surface area were obtained at $750{ }^{\circ} \mathrm{C}$.
\end{abstract}

Keywords: Caustic calcined magnesite, Calcination, Surface area, Porosity

*Sorumlu yazar (Corresponding author): Mehmet TÜRKMENOĞLU, mehmetturkmenoglu@yyu.edu.tr 
Farklı Kalsinasyon Sicakliklarında Elde Edilen Kostik Manyezitlerin Yüzey Alanlarının ve Porozitelerinin Belirlenmesi

\section{GíRiș}

Manyezit $\left(\mathrm{MgCO}_{3}\right)$, refrakter malzemelerin ana hammaddesi olup, saf manyezit $\% 47,81$ oranında magnezyum oksit (MgO) ve \%52,19 karbondioksitten $\left(\mathrm{CO}_{2}\right)$ oluşmaktadır. Ayrıca, manyezit cevheri içerisinde değişen oranlarda; karbonatlar, oksitler ve silikatlar bulunur. Doğada bulunuş şekliyle, iri kristaller halinde olanlara spatik manyezit, kriptokristalen halinde bulunanlara da jel manyezit adı verilmektedir [1].

Türkiye, manyezit rezervi açısından dünyada önemli bir yere sahiptir. Manyezit yataklarının kökeninin belirlenmesinde ve sinıflandırılmasında; manyezit oluşum şeklinin, yan kayacın kimyasal bileşiminin, manyezitin mineral içeriğinin ve jeokimyasal özelliklerin önemi vardır. Manyezitin kalitesi belirlenirken; $\mathrm{SiO}_{2}, \mathrm{Fe}_{2} \mathrm{O}_{3}, \mathrm{CaO}, \mathrm{Al}_{2} \mathrm{O}_{3}$ oranları önemlidir ve bu değerlere göre manyezitin ekonomik olup olmadığı değerlendirilmektedir. Türkiye'de manyezit yataklarının bulunduğu yerler Şekil 1'de verilmiştir [2].

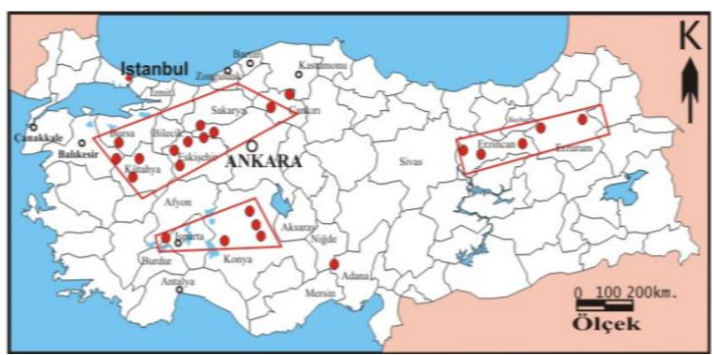

Şekil 1. Türkiye'de bulunan manyezit yatakları [2]

Manyezit madenciliğinde genellikle; tavuklama ve triyaj (el ile ayıklama), ağır ortam ile zenginleştirme, manyetik ayırma ile zenginleştirme, flotasyonla zenginleştirme ve diğer zenginleştirme yöntemleri kullanılmaktadır [1].

Tek başına çok fazla kullanım alanı olmayan manyezit, 1sıl işlem sonrası oluşan $\mathrm{MgO}$ formundan yola çıkılarak elde edilen; sülfat (oksisülfat çimento üretimi) [3], hidroksit [4,5], klorit (magnezyum oksiklorür çimento üretimi) [6,7], borat (magnezyum borat) [8] gibi formlarda birçok alanda kullanılmaktadır. Ayrıca; tarım endüstrisi, gübre endüstrisi, ilaç endüstrisi ve tıp alanı, kimya endüstrisi, lastik ve plastik endüstrisi, kâğıt endüstrisi ve otomotiv endüstrisi [9] ve refrakter tuğla yapımında [10] kullanılmaktadır.

Abalı [5] yaptığı çalışmada, \%97,35 $\mathrm{MgCO}_{3}$ içeren manyeziti $500{ }^{\circ} \mathrm{C}$ ile $900{ }^{\circ} \mathrm{C}$ arasındaki sıcaklıklarda kalsine etmiş ve kalsinasyon reaksiyonunun ikinci derecede ilerleyen bir reaksiyon olduğunu belirlemiştir. Elde ettiği sönmemiş manyezitlerden, asetik asitle söndürme ve sodyum hidroksitle çöktürme işlemleri ile magnezyum hidroksit elde etmiş ve son olarak, magnezyum hidroksitin $700{ }^{\circ} \mathrm{C}$ 'de kalsinasyonuyla saf magnezyum oksit elde etmiştir.

Manyezit cevheri, hedeflenen kullanım alanına göre farklı kalsinasyon sicaklıklarında kalsine edilmekte ve bu kalsinasyon sıcaklığına göre kostik (600-900 $\left.{ }^{\circ} \mathrm{C}\right)$ veya sinter manyezit $\left(1400-1700{ }^{\circ} \mathrm{C}\right)$ olarak siniflandirılmaktadır.

Kostik kalsine manyezitin ve sinter manyezitin hidroksilasyonu (veya hidrasyonu) ile ilgili yapılan çalışmaya [11] göre; magnezyum oksitin sönme reaksiyonu gerçekleşirken ilk oluşan magnezyum hidroksit tabakası daha sonraki sönme işlemini önleyerek yavaşlatmaktadır. İlk tabakanın hacimsel genişlemesi bir süre sonra yüzeyi sıkıştırmaya ve yeni çatlakların oluşumuna neden olarak, daha sonraki reaksiyonların başlamasını sağlamaktadır. Yüzey alanının küçük olduğu durumlarda hidrasyon reaksiyonu daha yavaş gerçekleşmekte (Şekil 2'de en yüksek yüzey alanı en yüksek dehidroksilasyon oranını vermekte), kostik kalsine manyezitin sönme reaksiyonunda daha çok 1sı ç1ktığ daha etkin reaksiyon vermektedir. Araştırmacılara göre; bu özellikler nedeniyle kostik kalsine manyezit polimerik kompozitlerin üretiminde, sinter manyezit ise refrakter tuğlaların imalinde avantajlı olmaktadır.

Manyezit mineralinin ilaç sanayisinde kullanımı olanaklarının incelendiği çalışmaya göre; Manyezit, pH 2 civarında mide asidi ile reaksiyon vermekte ve karbondioksit çıkışı sayesinde, tablet halindeki ilaçlarda parçalayıcı olarak kullanılabilmektedir. Ayrıca, manyezit minerali toksik olmadığı için, birçok ilaçta kalsitle birlikte seyreltici ve bağlayıcı olarak kullanılmaktadır [12]. 


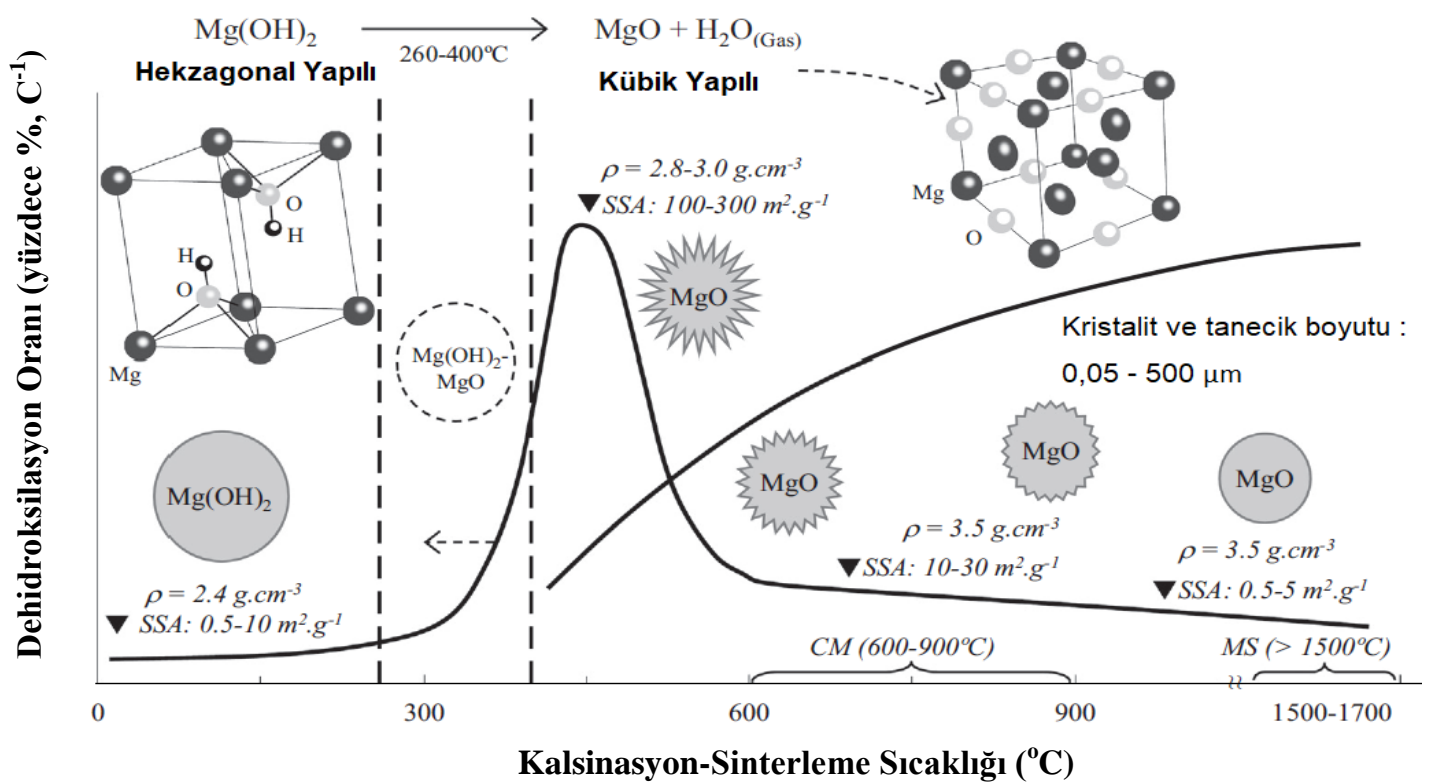

Şekil 2. Farklı sıcaklıklarda kalsine olmuş manyezitlerin dehidroksilasyon oranı (SSA: Spesifik yüzey alanı, CM: Kostik manyezit, MS: Sinter manyezit) [11]

Alvarado ve arkadaşları [13]; farklı magnezyum tuzlarından ve dolomit mineralinden magnezyum oksit tozlarının elde edilmesi ve karakterizasyonu üzerinde çalışmışlardır. Magnezyum sülfat hepta hidrat, magnezyum nitrat hegza hidrat, magnezyum asetat tetra hidrat ve kalsiyum magnezyum karbonat minerallerini kullanarak, $500{ }^{\circ} \mathrm{C}$ ile $1000{ }^{\circ} \mathrm{C}$ arasındaki sicaklıklarda elde ettikleri $\mathrm{MgO}$ tozlarında; XRD ile kristal yapı analizlerini, DTA/TGA ile minerallerin termal analizlerini, XRF ile kimyasal analizlerini, SEM ile morfolojik analizlerini yapmışlardır. Ayrıca; yoğunluk, spesifik yüzey alanı, aglomerasyon derecesi ve toplam gözeneklilik değerlerini belirlemişlerdir. Sinter manyezit üretiminde toz aktivitesi sinterleme için itici güç sağlamaktadır. Sülfat tuzunda; en düşük aglomerasyon derecesi, en düşük toplam porozite, en düşük tane boyutu ve en yüksek yüzey alanı değerleri belirlenmiştir. SEM görüntüleri sülfat tuzunun yüzey aktivitesinin en yüksek olduğunu göstermiştir.

Olijar ve arkadaşları [14], Manyezitin kostifikasyon prosesinin kinetiğinin optimizasyonunu incelemişlerdir. $650{ }^{\circ} \mathrm{C}$ ile $950{ }^{\circ} \mathrm{C}$ arasındaki sicaklıklarda, en az \%42 oranında $\mathrm{MgO}$ içeren, 0,25 $\mathrm{mm}$ ile 1,6 $\mathrm{mm}$ arasındaki farklı boyutlardaki manyezit cevherleri üzerinde gerçekleştirdikleri kalsinasyon işlemleri sonrasında, kalsinasyon süresini ve manyezitin aktifliğini belirlemişler ve bir matematiksel model oluşturmuşlardır. Kostik kalsine manyezit eldesinde en fazla $1200{ }^{\circ} \mathrm{C}$ sicaklık kullanılmakta ve daha sonra elde edilen kostik manyezitler $1700{ }^{\circ} \mathrm{C}$ 'de yakılarak sinter manyezit elde edilmektedir. Kostik kalsine manyezitin reaktif olmasının nedeni $70 \mathrm{~m}^{2} / \mathrm{g}$ ile $100 \mathrm{~m}^{2} / \mathrm{g}$ arasındaki yüzey alanına sahip olmasıdır. En yüksek reaktif değerler karbondioksit bozunmasının gerçekleştiği en düşük sıcaklıklar olan $650{ }^{\circ} \mathrm{C}$ ile $850{ }^{\circ} \mathrm{C}$ arasında gözlenmiştir. Ayrıca yazarlar, tane boyutu azaldıkça kalsinasyon miktarının arttığını, manyezitin $700{ }^{\circ} \mathrm{C}$ ile $850{ }^{\circ} \mathrm{C}$ arasında aktifleştiğini, daha yüksek kalsinasyon sıcaklıklarının kalsinasyon süresini kısalttığını ancak kostik kalsine manyezitin kalitesini düşürdüğünü ileri sürmüşlerdir.

Altıner ve arkadaşları [15] yaptıkları çalışmada; dolomit cevherini $\left(\mathrm{CaMg}\left(\mathrm{CO}_{3}\right)_{2}\right)$ ilk olarak hidroklorik asit $(\mathrm{HCl})$ ile çözeltiye almıştır. 
Farklı Kalsinasyon Sicakliklarında Elde Edilen Kostik Manyezitlerin Yüzey Alanlarının ve Porozitelerinin Belirlenmesi

Reaksiyon sırasında açığa çıkan $\mathrm{CO}_{2}$ gazı gazometre tankında bir sonraki aşamada değerlendirilmek üzere depolamıştır. Özütleme işlemini takiben; çözeltinin içerdiği kalsiyum iyonlarını hızlandırılmış mineral karbonizasyon yöntemiyle çöktürmüş ve kalsiyum karbonat olarak ortamdan uzaklaştırmışlardır [16]. Mineral karbonizasyon işlemi sonunda elde edilen magnezyum yönünden zengin çözeltiden ise; pirohidroliz-kalsinasyon yöntemi uygulayarak nano boyut dağılımına sahip $\mathrm{MgO}$ tanecikleri $\left(\mathrm{d}_{50}=180,05 \mathrm{~nm}\right)$ üretmişlerdir [17,18]. Üretim sıcaklığı ve aşama sayısının elde edilen $\mathrm{MgO}$ taneciklerinin kristal şekli ve tane boyutuna etki ettiği; reaksiyon sıcaklığının artmasına bağlı olarak $\mathrm{MgO}$ taneciklerinin sinterleşme özelliği göstererek aglomere olduğu ve mikronize boyutlarda $\mathrm{MgO}$ tanecikleri $\left(\mathrm{d}_{50}=6 \mu \mathrm{m}\right)$ elde edildiği belirlenmiştir. Benzer bulgular Mo ve arkadaşları [19] tarafindan da ortaya konmuştur.

$\mathrm{Bu}$ çalışmada ise; Konya/Çumra bölgesinden alınan manyezit cevherinin farklı kalsinasyon sıcaklıkları altındaki davranışı incelenmiştir. Kalsinasyon sıcaklığına bağlı olarak özgül yüzey alanı ve porozite özelliklerinin değişimi gözlenmiştir. Ayrıca; her bir aşamada elde edilen ürünlerin taramalı elektron mikroskobu ile görüntüleri elde edilmiş; sıcaklığın kristal yapısına olan etkileri ortaya konmuştur.

\section{MATERYAL VE METOT}

Çalışmada; Konya İli, Çumra İlçesi civarından alınan manyezit örnekleri kullanılmıştır. MTA Genel Müdürlüğü tarafından hazırlanan Türkiye Manyezit Envanteri'ne [1] göre; Konya İli sınırları içerisindeki tüm manyezit sahalarında, en yaygın ultra bazik kayaçlar altere olmuş serpantinitlerdir. Bu kayaçlar; yeşilimsi sarı, kırmızı, kahve ve pas renginin değişik tonlarındaki renkleriyle diğer kayaçlardan kolaylıkla ayırt edilebilirler. Cevherleşme, serpantinitler içinde küçüklü büyüklü kırık çatlaklar içerisinde genellikle ağsı ve damar şeklindedir. Bu cevherler ortalama olarak; \%2-6 aras1 $\mathrm{SiO}_{2}, \% 0,3-1,2$ aras1 $\mathrm{CaO}, \% 44-46$ arası $\mathrm{MgO}, \% 50-52$ arası ateşte zaiyat (kızdırma kaybı) değerlerine sahiptir [1].
Manyezit örnekleri, yaklaşık $10 \mathrm{~g}$ ağırlığında ve küp şeklinde hazırlanmış ve kül firını içerisinde; $650{ }^{\circ} \mathrm{C}$ ile $850{ }^{\circ} \mathrm{C}$ arasındaki sicaklıklarda 1 saat süreyle kalsinasyon işlemine tabi tutulmuşlardır. Ham Manyezit örneği agat havanda öğütülerek ağzı kilitli numune poşetlerinde saklanmıştır. Laboratuarda kül firınında çeşitli sıcaklıklarda üretilen ve ince boyutlu olan kostik manyezit örneklerinin nem alarak sönmemesi için soğutma işlemleri desikatörde gerçekleştirilmiştir.

KELVIN 1042 model Sorptometer cihazı (Şekil 3) ile; örnekler U şeklindeki tüpler içersinde, 6 örnekleme noktasına yerleştirilmiştir. Sıv1 azot içerisine $\left(-196{ }^{\circ} \mathrm{C}\right)$ daldırılan cam tüpler içerisindeki malzemenin yüzeyine adsorbe olan gaz miktarı ve desorbe olan gaz miktarı, gazların basınçlarının sürekli akış yöntemini kullanılarak ölçülmesi ile belirlenmiştir. Yüksek saflıktaki helyum gazı ile azot gazının 35 farklı orandaki konsantrasyonunun örnekler üzerinde, s1v1 azot ortamında adsorbsiyonunun ve desorpsiyonunun dedektörde ölçülmesi ile BET (Brunauer, Emmet ve Teller) ve Langmuir formüllerini kullanarak, katı örneklerin yüzey alanlarını belirlenmiştir. Ayrica, BJH (Barrett-Joyner-Halenda) metodu ile gözenek dağılımları hesaplanmıştır.

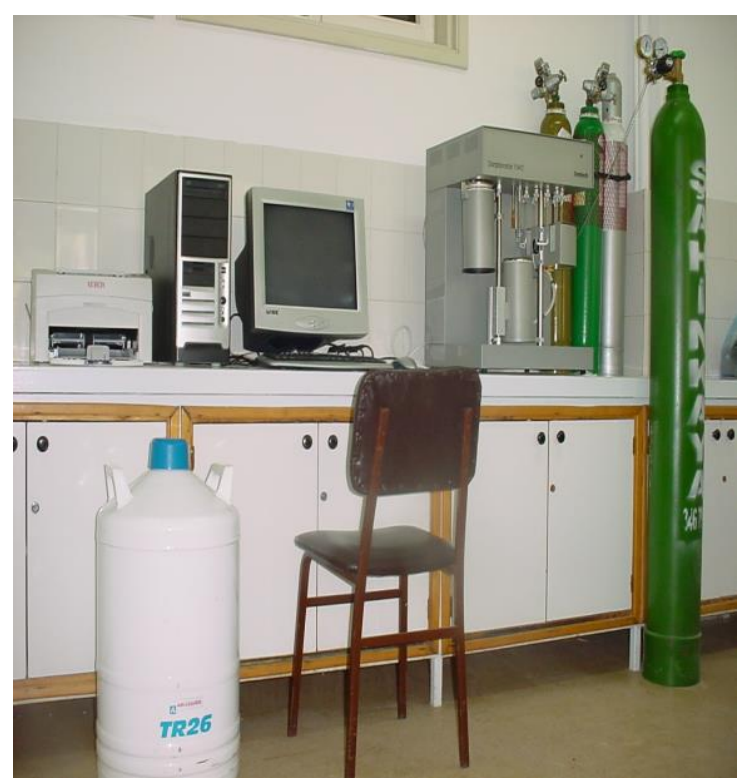

Şekil 3. Kelvin 1042 Sorptometre Cihazı 


\section{ARAŞTIRMA BULGULARI}

Manyezit örneğinin kimyasal bileşiminin belirlenmesi için yapılan analizler sonucunda Çizelge 1'de verilen sonuçlar elde edilmiştir.
İncelenen manyezit örneklerinin mineralojik özelliklerinin tespiti için XRD ve mikroskop çalışmaları yapılmış; ana parajenez mineralleri manyezit $(\% 96,59)$ ve dolomit $(\% 0,86)$ olarak tespit edilmiştir. Manyezit örneğine ait XRD grafiği Şekil 4’te verilmiştir.

Çizelge 1. Manyezitin kimyasal analiz sonuçları

\begin{tabular}{|c|c|}
\hline Parametre & Manyezit \\
\hline $\mathrm{MgO}-\mathrm{MgCO}_{3}$ & $\% 46,20-\% 97,02$ \\
\hline $\mathrm{CaO}-\mathrm{CaCO}_{3}$ & $\% 0,24-\% 0,43$ \\
\hline $\mathrm{SiO}_{2}$ & $\% 0,48$ \\
\hline $\mathrm{Fe}_{2} \mathrm{O}_{3}$ & $\% 0,40$ \\
\hline $\mathrm{Al}_{2} \mathrm{O}_{3}$ & $\% 0,22$ \\
\hline $\mathrm{Na}_{2} \mathrm{O}$ & $\% 1,32$ \\
\hline $\mathrm{K}_{2} \mathrm{O}$ & $\% 0,04$ \\
\hline $\mathrm{K} 1 \mathrm{izd}$ rma Kayb1 & $\% 46,40$ \\
\hline
\end{tabular}

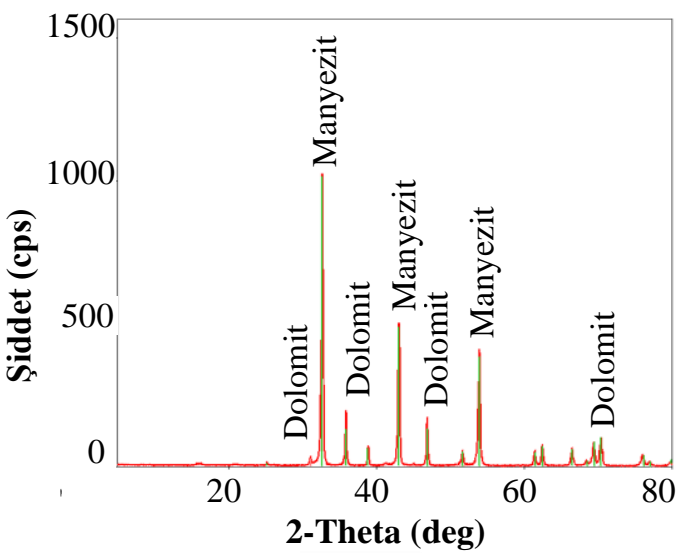

Şekil 4. Manyezit örneğine ait XRD diyagramı

\subsection{Yüzey Alanı ve Porozite Değerlerinin Belirlenmesi}

Örneklere ait BET yüzey alanları, Langmuir yüzey alanları, toplam gözenek hacimleri ve mikro gözenek hacimleri Çizelge 2'de verilmiştir. Çizelge 2'de verilen BET ve Langmuir yüzey alanı verileri ile toplam gözenek hacmi değerlerinin, farklı sicaklıklarda gösterdiği değişimler Şekil 5'de grafik üzerinde gösterilmiştir.

Kalsinasyon esnasında manyezitin bünyesindeki karbondioksit ne kadar verimli bir şekilde uzaklaştırılırsa, gözenek hacmi aynı oranda büyümektedir. Yüzey alanı büyüdükçe, kostik kalsine manyezitin aktifliği artmaktadır.

Toplam gözenek hacminin en yüksek olduğu, BET ve Langmuir yüzey alanlarının en yüksek olduğu kalsinasyon sıcaklığı, en kaliteli kostik kalsine manyeztin elde edilmesi için en optimum sıcaklıktır.

Kalsinasyon sicaklığı $650{ }^{\circ} \mathrm{C}$ iken, elde edilen kalsine manyezit örneğinin BET ve Langmuir yüzey alanı değerleri sırasıyla $63,77 \mathrm{~m}^{2} / \mathrm{g}$ ve $81,34 \mathrm{~m}^{2} / \mathrm{g}$ olarak belirlenmiştir. Kalsinasyon sıcaklığ $750{ }^{\circ} \mathrm{C}$ olduğunda ise en yüksek BET ve Langmuir yüzey alanı değerlerine sahip kalsine manyezit örnekleri elde edilmiştir. Ancak, daha yüksek kalsinasyon sicaklıklarında elde edilen örneklerin özgül yüzey alanı değerleri düşme eğilimi göstermiştir. $\mathrm{Bu}$ durum, kalsinasyon sıcaklığının artmasına bağlı olarak manyezit taneciklerinin sinterleşme özelliği göstermesi ile açıklanabilmektedir. Literatürde de benzer sonuçlar diğer araştırmacılar tarafindan ortaya konmuştur [18,19]. Sonuç olarak; kalsinasyon sıcaklığının artmasına bağlı olarak elde edilen ürünlerin yüzey alanı değerlerinde düşüş gerçekleşmiştir. 
Farklı Kalsinasyon Sicaklıklarında Elde Edilen Kostik Manyezitlerin Yüzey Alanlarııın ve Porozitelerinin Belirlenmesi

Çizelge 2. Manyezit örneğine ve kostik kalsine manyezit örneklerine ait yüzey alanı ve porozite sonuçları

\begin{tabular}{|c|c|c|c|c|c|c|c|}
\hline \multirow{2}{*}{ Manyezit $\left(\mathrm{MgCO}_{3}\right)$} & \multirow{2}{*}{ Birim } & \multirow{2}{*}{$\begin{array}{c}\text { Orjinal } \\
\text { Örnek } \\
\text { (Kalsine } \\
\text { olmamış) }\end{array}$} & \multicolumn{5}{|c|}{ Kostik Kalsine Manyezit Örnekleri } \\
\hline & & & $650^{\circ} \mathrm{C}$ & $700{ }^{\circ} \mathrm{C}$ & $750^{\circ} \mathrm{C}$ & $800{ }^{\circ} \mathrm{C}$ & $850{ }^{\circ} \mathrm{C}$ \\
\hline BET Yüzey alanı & $\left(\mathrm{m}^{2} / \mathrm{g}\right)$ & 2,71 & 63,77 & 65,81 & 70,49 & 50,61 & 48,85 \\
\hline Langmuir Yüzey Alanı & $\left(\mathrm{m}^{2} / \mathrm{g}\right)$ & 3,45 & 81,34 & 84,70 & 91,29 & 64,92 & 62,92 \\
\hline Toplam Gözenek Hacmi & $\left(\mathrm{mm}^{3} / \mathrm{g}\right)$ & 5,89 & 116,23 & 117,95 & 172,70 & 123,85 & 134,35 \\
\hline Mikro Gözenek Hacmi & $\left(\mathrm{mm}^{3} / \mathrm{g}\right)$ & 0,03 & 0,00 & 0,00 & 0,00 & 0,00 & 0,00 \\
\hline Kızdırma Kaybı & $(\%)$ & 46,40 & 6.05 & 4.43 & 3.72 & 3.08 & 2.69 \\
\hline
\end{tabular}

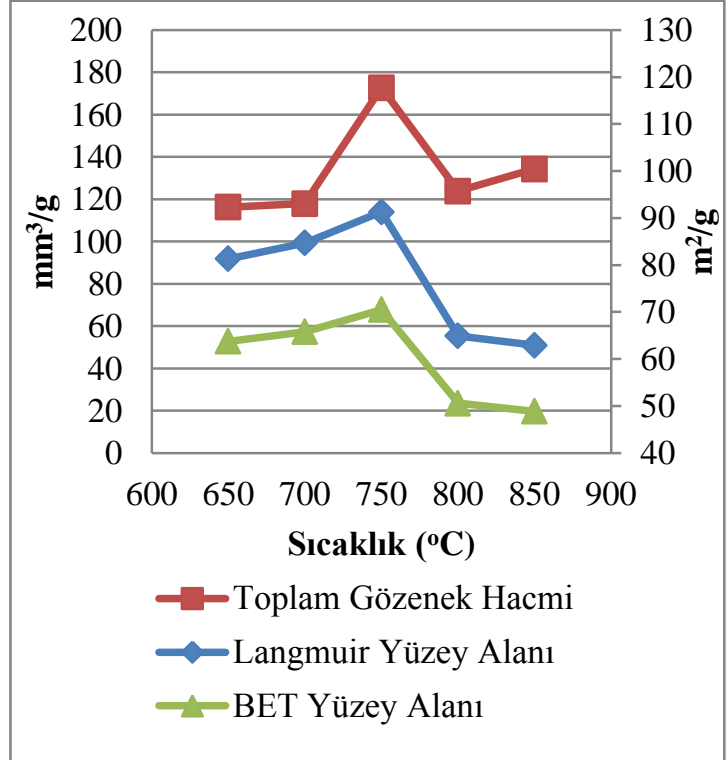

Şekil 5. BET ve Langmuir yüzey alanı verileri ile toplam gözenek hacmi değerlerinin, farklı kalsinasyon sıcaklıklarındaki değişimi

Dolomit mineralinin $\left(\mathrm{CaMg}\left(\mathrm{CO}_{3}\right)_{2}\right)$ kalsinasyonu için $650{ }^{\circ} \mathrm{C}$ yeterliyken, kalsit mineralinin $\left(\mathrm{CaCO}_{3}\right)$ kalsinasyonu için $900{ }^{\circ} \mathrm{C}$ gerekmektedir. Kalsinasyon sıcaklığının doğru bir şekilde belirlenmesi tesislerde yakıt tasarrufu sağlamakla birlikte, elde edilen ürünün kalitesini de etkilemektedir. Manyezit mineralinin kalsinasyonu için teorik olarak $750^{\circ} \mathrm{C}$ yeterlidir (Şekil 5).

\subsection{SEM Analizleri}

Kalsine olmamış manyezit örneği ile birlikte; 650 , $700,750,800$ ve $850{ }^{\circ} \mathrm{C}$ sicaklıklarda kalsine olmuş kostik kalsine manyezit örneklerinin SEM görüntüleri çekilmiştir. Kostik kalsine manyezit örneklerine ait SEM görüntüleri Şekil 6 a.b.c.d.e.f'de verilmiştir. Manyezitin $800{ }^{\circ} \mathrm{C}$ ve $850^{\circ} \mathrm{C}$ 'deki SEM görüntüleri incelendiğinde, artan sıcaklıkla birlikte daha önce açılan gözeneklerin tekrar kapanmaya başladığı ve kristal tane boyutunun büyüdüğü görülmektedir. BET ve Langmuir değerleri ile SEM görüntüleri kıyaslandığında, elde edilen sonuçların birbirini destekler nitelikte olduğu açıktır.

Kalsinasyon işlemine maruz kalan manyezitin kostik özellik gösterebilmesi (su ile reaksiyona girmesi) için yüzey alanının mümkün olduğunca yüksek olması gerekmektedir. Altıner ve Yıldırım [18] yaptıkları çalışmada ürettikleri MgO'nun reaktivite özelliğinin sicaklığa bağlı olarak düştüğünü, $800{ }^{\circ} \mathrm{C}$ ve daha yüksek sıcaklıklarda üretilen $\mathrm{MgO}$ 'nun su ile reaksiyona girerek kostik özellik göstermesi ve $\mathrm{Mg}(\mathrm{OH})_{2}$ 'ye dönüşüm oranının da oldukça düşük olduğunu belirtmişlerdir. Reaktivite özelliği düşük manyezit refrakter, malzeme olarak yüksek sıcaklıklara ve basınca dayanıklılık gerektiren yerlerde kullanılmaktadır. 


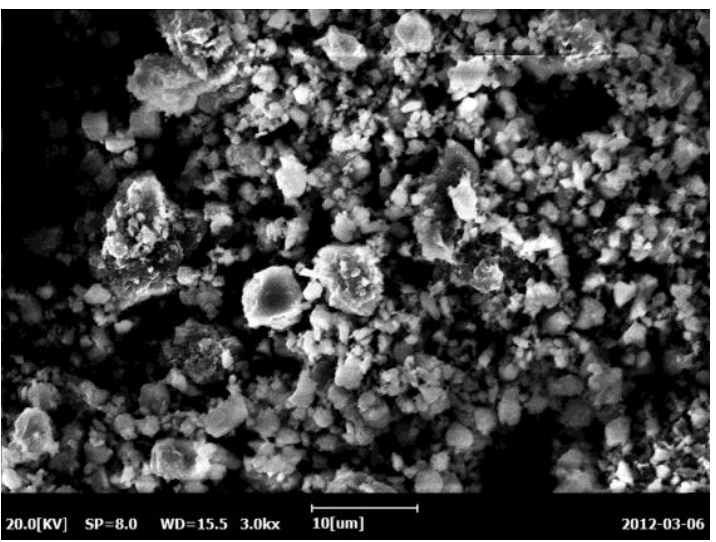

Şekil 6.a. Orijinal manyezit örneğine ait SEM görüntüsü

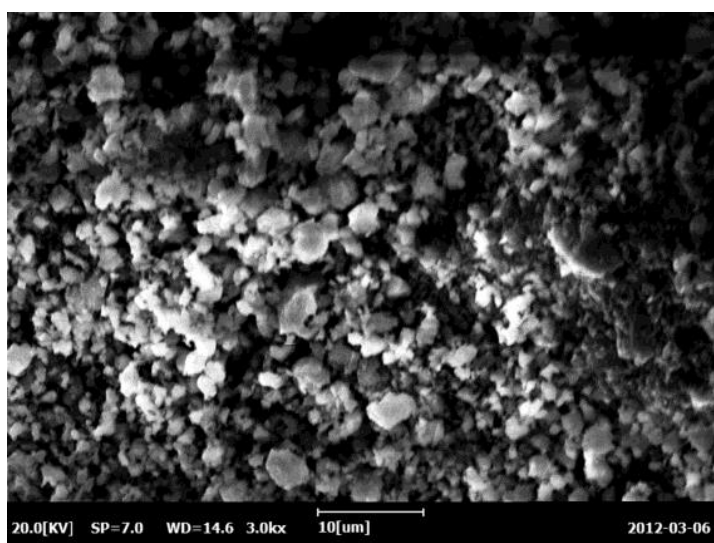

Şekil 6.b. $650{ }^{\circ} \mathrm{C}$ 'de üretilmiş kostik kalsine manyezit örneğine ait SEM görüntüsü

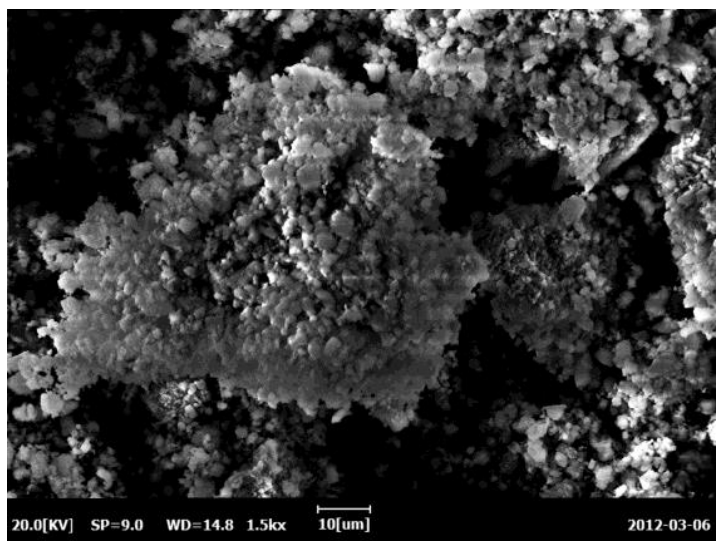

Şekil 6.c. $700{ }^{\circ} C^{\prime}$ de üretilmiş kostik kalsine manyezit örneğine ait SEM görüntüsü

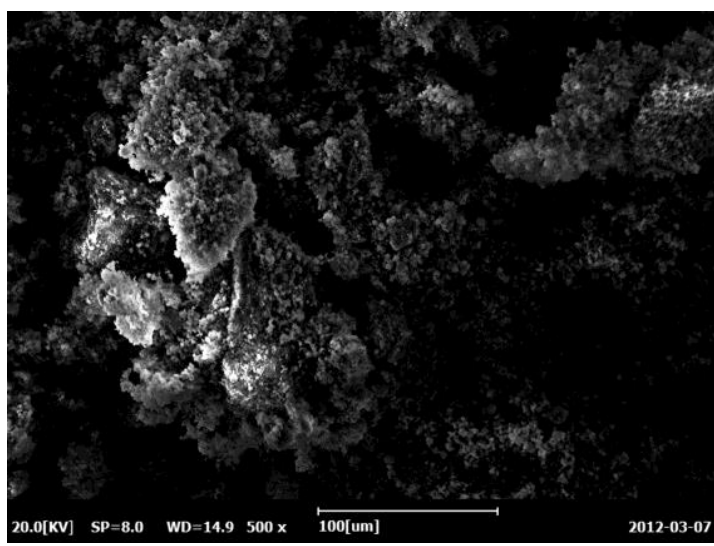

Şekil 6.d. $750{ }^{\circ} \mathrm{C}$ 'de üretilmiş kostik kalsine manyezit örneğine ait SEM görüntüsü

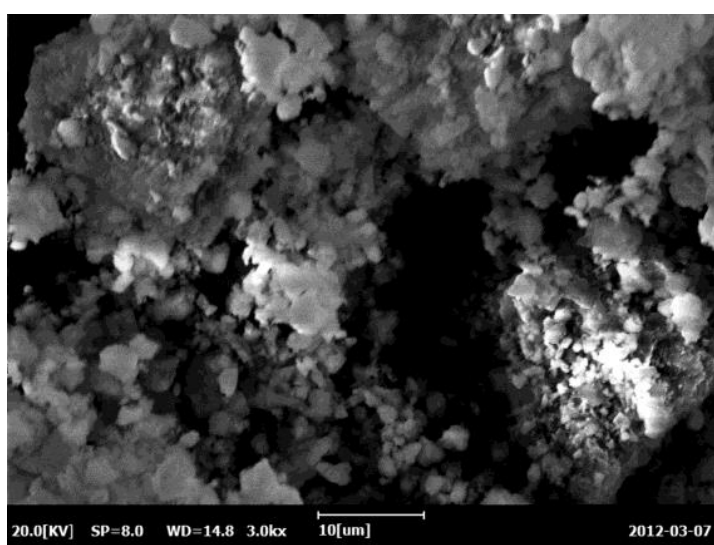

Şekil 6.e. $800{ }^{\circ} \mathrm{C}^{\prime} \mathrm{de}$ üretilmiş kostik kalsine manyezit örneğine ait SEM görüntüsü

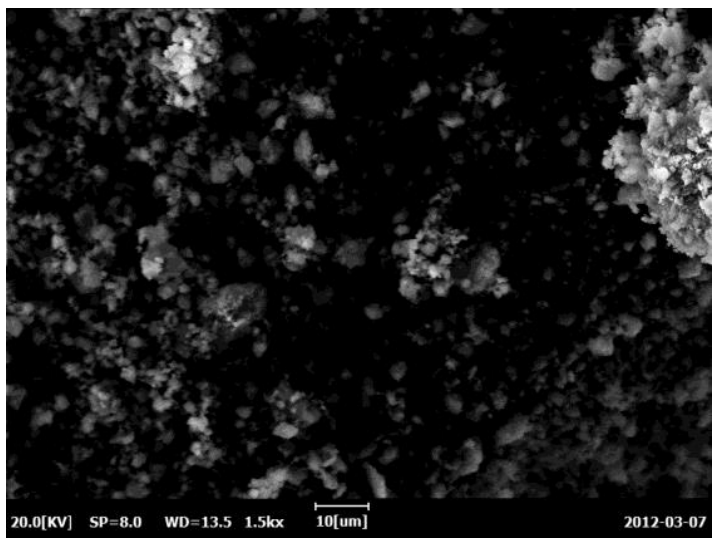

Şekil 6.f. $850{ }^{\circ} \mathrm{C}^{\prime} \mathrm{de}$ üretilmiş kostik kalsine manyezit örneğine ait SEM görüntüsü 
Farklı Kalsinasyon Sicaklıklarında Elde Edilen Kostik Manyezitlerin Yüzey Alanlarının ve Porozitelerinin Belirlenmesi

\section{SONUÇLAR ve ÖNERİLER}

Konya İli, Çumra İlçesinden alınan manyezit örneklerinin $650 \quad{ }^{\circ} \mathrm{C}$ ile $850 \quad{ }^{\circ} \mathrm{C}$ arasındaki sıcaklıklarda kalsine edilmesi ile elde edilen verilerin değerlendirilmesi ile aşağıdaki sonuçlara ve önerilere ulaşılmıştır.

- Orijinal örneğe ait XRD diyagramı ve kimyasal analiz sonuçları, örneğin manyezit minerali olduğunu göstermiştir. Örneğe ait kızdırma kaybı deney sonucunun yüksek çıkması, bileşiminde karbonat oranının yüksek olmasından kaynaklanmaktadır.

- Orijinal manyezit örneğinin yüzey alanı, kalsinasyon sirasinda artan sicaklıkla birlikte mineral bünyesindeki karbondioksitin uzaklaşması ile 30-35 kat artmıştır. Literatürdeki çalışmaların da desteklediği gibi, yüzey alanının artması kostik kalsine manyezitin aktifliğini ve su ile reaksiyona girme hızını arttırmaktadır. İnşaat sektöründe çimento ile birlikte bağlayıcılık özelliği sağlaması açısından MgO'nun aktif olması istenmektedir.

- BET (Brunauer, Emmet ve Teller) formülü ile hesaplanan yüzey alanlarında en yüksek değer $750{ }^{\circ} \mathrm{C}^{\prime} \mathrm{de}\left(70,49 \mathrm{~m}^{2} / \mathrm{g}\right)$ görülmüştür.

- Langmuir formülü ile hesaplanan yüzey alanlarında en yüksek değer yine $750{ }^{\circ} \mathrm{C}$ 'de $91,29 \mathrm{~m}^{2} / \mathrm{g}$ olarak belirlenmiştir.

- BJH (Barrett-Joyner-Halenda) metodu ile hesaplanan gözenek dağılımları incelendiğinde, en yüksek toplam gözenek hacmi $750{ }^{\circ} \mathrm{C}$ 'de $172,70 \mathrm{~mm}^{3} / \mathrm{g}$ olarak ölçülmüştür.

- $750{ }^{\circ} C^{\prime}$ ye kadar, kalsine olan kostik kalsine manyezitlerin yüzey alanları ve gözenek hacimleri artmaya devam etmiş, bu sicaklıktan sonra açılan gözeneklerin tekrar kapanmaya başladığ1 gözlenmiştir.

- Kalsine olmamış \%97 saflıktaki orijinal manyezit örneğinde $0,03 \mathrm{~mm}^{3} / \mathrm{g}$ olarak ölçülen mikro gözenek hacmi, kalsine olmuş hiçbir örnekte belirlenmemiştir. Yani kostik kalsine manyezitlerde mikro gözenek bulunmamaktadir.

- TS 8542 Kasim 1990, "Manyezit-refrakter sanayinde kullanılan" standardına [20] göre Çizelge 3'te verilen bileşime sahip olmalıdır. Kullanılan manyezit örneği standartta verilen tüm değerleri sağlamaktadır.

Çizelge 3. Standart değerler [20]

\begin{tabular}{|c|c|c|c|}
\hline \multirow{2}{*}{ Bileşim } & \multicolumn{3}{|c|}{ \% Miktarca kütle } \\
\hline & En az & En çok & Örnek \\
\hline MgO & 40,0 & - & 46,20 \\
\hline $\mathrm{SiO}_{2}$ & - & 3,0 & 0,48 \\
\hline $\mathrm{CaO}$ & - & 3,0 & 0,24 \\
\hline $\mathrm{Fe}_{2} \mathrm{O}_{3}$ & - & 1,0 & 0,40 \\
\hline $\mathrm{CaO} / \mathrm{SiO}_{2}$ & 0,2 & 2,0 & 0,5 \\
\hline Kızdırma kaybı & - & 52,0 & 46,4 \\
\hline
\end{tabular}

- Manyezit kalsinasyon tesislerinde yakıt tasarrufu sağlanabilmesi için kalsinasyonun $900{ }^{\circ} \mathrm{C}-1000{ }^{\circ} \mathrm{C}$ gibi yüksek sicaklıklarda değil, teorik olarak $750{ }^{\circ} \mathrm{C}$ 'de gerçekleştirilmesi yeterlidir. Ancak, her türlü kalsinasyonun pratikte teorik yeterli olan sicaklıktan daha yüksek sıcaklıklarda yapıldığı unutulmamalıdır. Daha düşük sicaklıklarda enerji tasarrufu sağlansa bile, diğer yandan başka maliyetler ve kapasite sorunu ortaya çıkabilir.

- TSE K 356 Mart 2015, "Kalsine Manyezit", standardına [21] göre Çizelge 4'te verilen değerleri sağlamalıdır.

Çizelge 4. Kalsine manyezitin fiziksel ve kimyasal özellikleri [21]

\begin{tabular}{|c|c|}
\hline Özellik & İstenen Değer \\
\hline Tane Büyüklüğü & $74 \mu \mathrm{m}-3 \mathrm{~cm}$ \\
\hline pH (\%10'luk çözeltide) & $7-8$ \\
\hline $\operatorname{MgO}(\% \mathrm{~m} / \mathrm{m})$ & $77-95$ \\
\hline $\mathrm{SiO}_{2}(\% \mathrm{~m} / \mathrm{m})$ & $1,5-20$ \\
\hline $\mathrm{CaO}(\% \mathrm{~m} / \mathrm{m})$ & $1,5-5$ \\
\hline $\mathrm{Fe}_{2} \mathrm{O}_{3}(\% \mathrm{~m} / \mathrm{m})$ & $0,10-0,75$ \\
\hline $\mathrm{Al}_{2} \mathrm{O}_{3}(\% \mathrm{~m} / \mathrm{m})$ & $0,01-0,05$ \\
\hline Kızdırma kaybı $(\% \mathrm{~m} / \mathrm{m})$ & $2,5-10$ \\
\hline
\end{tabular}


Kullanılan manyezit örneği kızdırma kaybı açısından standartlara uygundur.

- İncelenen manyezit örneği; başta ilaç sanayi ve kompozit malzeme üretimi olmak üzere, inşaat sanayinde ve diğer ilgili tüm sektörlerde; kostik kalsine manyezit, sinter manyezit veya saf manyezit üretiminde kullanıma uygundur.

\section{KAYNAKLAR}

1. Türkiye Manyezit Envanteri, 2011. MTA (Maden Tetkik Arama) Genel Müdürlüğü Envanter serisi: 203, Ankara.

2. Yılmaz A., Kuşcu M., 2012. Manyezit Yataklarının Oluşumu, Sinıflandırılması, Kullanım Alanları ve Kalite Sinıflandırılması. Erciyes Üniversitesi Fen Bilimleri Enstitüsü Dergisi, 28(1), 65-72.

3. Uğur, Ç., 2010, Asmaş Manyezit İşletmesi Triyaj Ara Ürünü ve $-20 \mathrm{~mm}$ Manyezit Atıklarının Değerlendirilmesi. Yüksek Lisans Tezi, Eskişehir Osmangazi Üniversitesi Fen Bilimleri Enstitüsü.

4. Erdoğan, N., 2013. Atık Manyezit Tozlarının Geri Kazanımı. Ekoloji Dergisi, sayı 22, (86) 75-83.

5. Abalı, Y., 2000. Magnezitin Kalsinasyon Kinetiği ve Saf $\mathrm{MgO}$ Üretimi. Selçuk Üniversitesi Fen-Edebiyat Fakültesi Fen Dergisi (17), 159-164.

6. Liu, Z., Wang, S., Huang, J., Wei, Z., Guan, B., Fang, J., 2015. Experimental Investigation on the Properties and Microstructure of Magnesium Oxychloride Cement Prepared With Caustic Magnesite and Dolomite. Construction and Building Materials, 85, 247-255.

7. Altıner, M., Yıldırım, M., 2017. Study of Using Dolomite as Starting Material Resource to Produce Magnesium Oxychloride Cement. Journal of Advanced Concrete Technology Vol. 15, 269-277.

8. Kıpçak, A.S., 2013. Çeşitli Magnezyum ve Bor Kaynaklarından Farklı Yöntemler ile Yapay Magnezyum Borat Üretimi ve Üretim Parametrelerinin İncelenmesi. Doktora tezi, Yıldız Teknik Üniversitesi Fen Bilimleri Enstitüsü.
9. Topak, Y., 2006. Yukarıtırtar-Aşağıtırtar Köyleri (Isparta kuzey doğusu) Arasında Gözlenen Manyezit Yatağının Oluşumu ve Kökeni. Doktora Tezi, Çukurova Üniversitesi Fen Bilimleri Enstitüsü.

10. Birchall, V.S.S., Rocha, S.D.F., Ciminelli, V.S.T., 2000. The Effect of Magnesite Calcination Conditions on Magnesia Hydration. Miner Engineering, vol.13, 1629-1633.

11. Salomao, R., Arruda, C.C., Kawamura, A.M., 2015. A Systemic Investigation on the Hydroxylation Behavior of Caustic Magnesia and Magnesia Sinter. Ceramics International 41 (2015) 13998-14007.

12. Carretero, I.M., Pezo, M., 2009. Clay and Nonclay Minerals in the Pharmaceutical Industry Part I. Excipients and Medical Applications. Applied Clay Science 46, 73-80.

13. Alvarado, E., T-Martinez, L.M., Fuentes, A.F., Quintana, P., 2000. Preparation and Characterization of $\mathrm{MgO}$ Powders Obtained from Different Magnesium Salts and the Mineral Dolomite. Polyhedron 19, 2345-2351.

14. Olijar A., Lisuch J., Dorcak D., Spisak J., 2010. The Proposal for Optimization the Kinetics of the Process the Caustification of Magnesite. Acta Montanistica Slovaca, Roçnik 15, Çislo 3, 244-247.

15. Altıner, M., Yıldırım M., Yılmaz, T., 2016. Leaching of Mersin/Aydıncık Dolomite Ore in Hydrochloric Acid. Dissolution rates. Pyhsicochemical Problems of Mineral Processing, Vol. 52, 536-550.

16. Altıner, M., Yıldırım, M., 2017. Production and Characterization of Synthetic Aragonite Prepared from Dolomite by Eco-friendly Leaching-carbonation Process. Advanced Powder Technology, Vol. 2, 553-564.

17. Altıner, M., Yildirim, M., 2017. Aydıncık/Mersin Dolomitlerinden Nano Boyut Dağılımına Sahip Sentetik Periklas (MgO) Taneciklerinin Üretimi, Türkiye Uluslararas1 Madencilik Kongresi, 11-14 Nisan 2017, Antalya, 813-822.

18. Altıner, M., Yildirım, M. 2017. Preparation of Periclase $(\mathrm{MgO})$ Nanoparticles from Dolomite by Pyrohydrolysis-Calcination Processes, 
Farklı Kalsinasyon Sicaklıklarında Elde Edilen Kostik Manyezitlerin Yüzey Alanlarının ve Porozitelerinin Belirlenmesi

Asia-Pacific Journal of Chemical Engineering, (Basım Aşamasında).

19. Mo, L., Deng, M., Tang, M. Effects of Calcination Condition on Expansion Property of MgO-type Expansive Agent Used in Cement-Based Materials. Cem. Concr. Res. 40: 437-446.

20.TS 8542 Kasim 1990. Manyezit-Refrakter Sanayinde Kullanılan. Türk Standartları Enstitüsü, Ankara.

21. TSE K 356 Mart 2015. Kalsine Manyezit. Türk Standartları Enstitüsü, Ankara. 